\title{
A SUSTENTABILIDADE COMO \\ OPORTUNIDADE DE NEGÓCIO \\ PARA OS CENTROS DE SERVIÇOS \\ COMPARTILHADOS
}

Luís Fabiano Celestrino ${ }^{1}$

\section{Resumo}

A sustentabilidade é fonte de iniciativas inovadoras para tornar os produtos e serviços mais atrativos. O Centro de Serviços Compartilhados (CSC), visto como propulsor das áreas de negócio, é o repositório natural dos serviços ligados à sustentabilidade de seus clientes. Este trabalho pretende propor um roteiro para prestação de serviço que incremente a sustentabilidade dos usuários do CSC. Foi realizada uma pesquisa sistemática sobre o tema Sustentabilidade em Centro de Serviços Compartilhados para prover a percepção de como esse tema está sendo expresso na literatura. Realizou-se, portanto, um levantamento bibliográfico da questão do serviço, em seguida sobre o Centro de Serviços Compartilhados, abordando a questão da qualidade do serviço, para então chegar ao Acordo de Nível de Serviço como instrumento da gestão da satisfação do cliente e do registro das diversas interações necessárias entre o CSC (fornecedor) e seu cliente. Para propor um exemplo de serviço de apoio à sustentabilidade dos clientes de um CSC, foi descrito um sistema de gestão que está inserido na dimensão ambiental: Gestão de Energia.

Palavras-Chave: TI - Centro de Serviços Compartilhados. Acordo de Nível de Serviço. Sustentabilidade. Gestão de Energia. 


\section{INTRODUÇÃO}

Que talutilizar a sustentabilidade como elemento catalisador de diferenciais para seus clientes? Esta é a pergunta que este trabalho direciona aos Centros de Serviços Compartilhados, pretendendo oferecer elementos para compor uma resposta adequada.

A sustentabilidade ainda desempenha papel secundário para muitos dos gestores que ousam repensar suas estratégias. Porém, como demonstraram Kim e Mauborgne (2005), a distância da área dos tubarões aumenta com a valorização que um negócio provê aos clientes.

\section{A SUSTENTABILIDADE REPRE-}

SENTA ÁGUAS TRANQUILAS E

AMPLAS, JÁ QUE SEUS PILARES

DE ECONOMIA (CUSTOS E LU-

CROS), AMBIENTE (CONTEXTOS)

E SOCIEDADE (PESSOAS) EN-

VOLVEM SISTEMAS COM MUITOS

AGENTES, PORTANTO, MUITOS A

SEREM BENEfICIADOS.
Para medir e entender a influência do conceito de sustentabilidade no CSC foi realizada uma revisão de literatura que abordou desde os conceitos básicos, tais como definição de serviço, de CSC, a qualidade do serviço e de Acordo de Nível de Serviço (ANS), considerando este ANS como instrumento da gestão da satisfação do cliente, além de ser base para o registro das diversas interações necessárias entre o CSC (fornecedor) e seu cliente. Como resultado deste estudo, foi descrito um sistema de gestão que está inserido na dimensão ambiental - a Gestão de Energia - produzindo um roteiro para a prestação deste serviço e um modelo genérico de ANS.

O objetivo geral deste artigo é elaborar um modelo de ANS para apoio à sustentabilidade dos processos dos clientes de um CSC. Os objetivos específicos são: situar a sustentabilidade como ponto estratégico na oferta de serviços do CSC; avaliar a aplicação de serviços de apoio à sustentabilidade dos processos dos clientes de um CSC; e apresentar um roteiro para prestação de serviço de apoio à sustentabilidade dos processos dos clientes de um CSC.

Incrementar o desenvolvimento do CSC com a oferta de "serviços de sustentabilidade" aparece como alternativa de trazer necessidades comuns a todos devido à abrangência do tema "sustentabilidade". 


\section{O Negócio dos Serviços e os Centros de Serviços Compartilhados}

Constatou-se a pouca e quase ausente menção de serviços de apoio à sustentabilidade a clientes do CSC com algumas contribuições na área de índices de desempenho em Monteiro et al. (2003), oportunidades de negócios sustentáveis em Makower (2009) e vários trabalhos sobre as indústrias petroquímicas que necessitam atrelar a dimensão da sustentabilidade ao seu negócio. (BAYARDINO, 2004; ENGEL, 2012). Nenhum, porém, trazia exemplos de serviços prestados pelo CSC focados em apoiar a sustentabilidade dos clientes.

Grönroos (2009) afirma que o serviço, na conotação de bem intangível,sempre esteve presente nas relações de troca comerciais ou não. Porém, na forma como as sociedades mediam sua riqueza, especialmente na Era Industrial (que inicia em meados do século XVIII e conclui no fim do século XX), o foco estava principalmente na produção de bens tangíveis, enquanto que os intangíveis eram subestimados. A divisão se dava em três setores principais: industrial, comercial e de serviços. O referido autor afirma que essa classificação é enganadora porque "negligencia os serviços ocultos nas manufaturas e na agricultura" e "vê os serviços como um 'setor' da economia, não como uma perspectiva de como criar uma vantagem competitiva". (GRÖNROOS, 2009, p. 2).

$\mathrm{Na}$ concepção de Grönroos (2009), as atividades empresariais podem apresentar quatro perspectivas estratégicas possíveis, que melhor definem a geração de valor a que se propõem:

- perspectiva de serviço;

- perspectiva de produto central;

- perspectiva de preço;

- perspectiva de imagem.

O quadro 1 apresenta a caracterização das perspectivas discutidas por Grönroos (2009): 


\begin{tabular}{|c|c|}
\hline $\begin{array}{l}\text { Perspectiva } \\
\text { estratégica }\end{array}$ & Características de uma abordagem estratégica correspondente \\
\hline $\begin{array}{c}\text { Perspectiva } \\
\text { de serviço }\end{array}$ & $\begin{array}{l}\text { A empresa adota a visão de que uma oferta aprimorada é exigida para apoiar os processos } \\
\text { de geração de valor do cliente e que a solução central, seja um produto físico, serviço } \\
\text { ou combinação de bens e serviços não é suficiente para diferenciar sua oferta daquelas } \\
\text { dos concorrentes. Componentes do produto físico, componentes do serviço, informação, } \\
\text { atenção pessoal e outros elementos dos relacionamentos com clientes são combinados em } \\
\text { uma oferta total de serviços. A oferta é denominada oferta de serviço, embora a solução } \\
\text { central possa ser baseada em um produto físico, porque todos os elementos da oferta são } \\
\text { combinados para prover um serviço que gera valor para os clientes. Desenvolver tal pacote } \\
\text { total de serviço é considerado de importância estratégica e, portanto, a administração lhe } \\
\text { confere a mais alta importância. Serviços ocultos, cobráveis e não cobráveis, são conside- } \\
\text { rados parte dessa oferta e apoiadores dos processos de criação de valor do cliente. O preço } \\
\text { é considerado menos importante para os clientes do que os custos em longo prazo. Uma } \\
\text { empresa que adota uma perspectiva de serviço é considerada uma empresa de serviços. }\end{array}$ \\
\hline $\begin{array}{c}\text { Perspectiva } \\
\text { de produto } \\
\text { central }\end{array}$ & $\begin{array}{l}\text { A empresa concentra-se no desenvolvimento da solução central, seja ela um produto físico } \\
\text { ou um serviço, como o principal provedor de valor para os processos de criação de valor } \\
\text { do cliente (o uso que o cliente faz das soluções para criar valor para si próprio ou para um } \\
\text { usuário organizacional). Serviços adicionais podem ser considerados necessários, mas não } \\
\text { de importância estratégica e, portanto, têm um baixo grau de prioridade. Serviços ocultos, } \\
\text { especialmente os não cobráveis, não são reconhecidos como serviços que aprimoram o valor. } \\
\text { A empresa diferencia seu pacote dos outros por fornecer uma excelente solução central. }\end{array}$ \\
\hline $\begin{array}{l}\text { Perspectiva } \\
\text { de preço }\end{array}$ & $\begin{array}{l}\text { A empresa adota a visão de que o preço é o critério de compra dominante de seus clientes e } \\
\text { que poder oferecer um preço baixo é uma necessidade para a sobrevivência no mercado. O } \\
\text { preço é visto como a principal contribuição aos processos de criação de valor dos clientes. } \\
\text { O fornecimento de serviços adicionais não é considerado algo que aprimora o valor e é, } \\
\text { portanto, de prioridade mais baixa do que os efeitos e custo em longo prazo de uma solução. } \\
\text { A empresa está diferenciando sua oferta por ser a alternativa mais barata disponível ou } \\
\text { uma das mais baratas. }\end{array}$ \\
\hline $\begin{array}{l}\text { Perspectiva } \\
\text { de imagem }\end{array}$ & $\begin{array}{l}\text { A empresa diferencia sua oferta criando extras imaginários (uma imagem de marca) ao } \\
\text { redor de seu produto. Esses extras são criados principalmente na mente dos clientes por } \\
\text { propaganda e comunicação de marketing. A solução central é vista como um ponto de } \\
\text { partida para o desenvolvimento de valor para o cliente, mas a imagem de marca que é } \\
\text { criada pelo marketing é considerada a contribuição mais importante para os processos de } \\
\text { criação de valor do cliente. }\end{array}$ \\
\hline
\end{tabular}

Fonte: Grönroos (2009) 
Num movimento natural de especificação e competitividade, surge o modelo organizacional do Centro de Serviços Compartilhados (CSC), focado na perspectiva estratégica de serviço, relacionando-se com clientes que necessitam de apoio do tipo outsourcing em atividades (serviços) que agregam valor secundário a seus negócios.

Algumas palavras de ordem para a adoção do CSC como medida estratégica para a competitividade de uma organização são:

- redução de custos;

- padronização;

- melhoria de qualidade em serviços de apoio.

Segundo Soares e Runte (2012), “o CSC é uma estrutura interna que tem como objetivo centralizar as atividades de suporte da empresa, a fim de obter ganhos de escala, padronização dos processos e, ao mesmo tempo, permitir que as unidades de negócio foquem no seu core business."

$\mathrm{O}$ aspecto fundamental para a prosperidade do CSC numa corporação é a qualidade do serviço oferecido, já que a redução de custo é um motivador que será relevado caso o benefício alcançado pela economia da implantação do CSC não seja maior ou igual ao anterior, uma vez que o preço da qualidade de um serviço é um ponto subjetivo e, não rara vez, fundamental para a estratégia e competitividade do negócio.

Madalozzo (2012) explicita a relação entre custo e qualidade, o que é descrito na figura 1.
Figura 1: Relação entre custo e qualidade do serviço

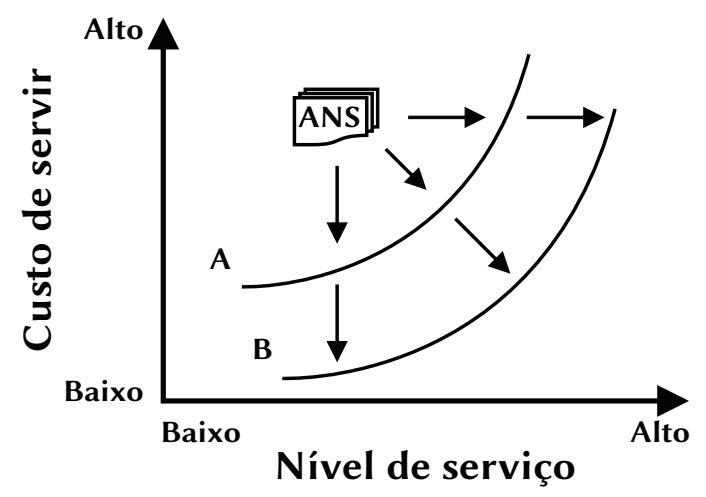

Fonte: Madalozzo (2012)

Na representação de Madalozzo (2012), a diferença entre as curvas A e B acontece pela diferença na maturidade da prestação do serviço, onde B é mais maduro que A. O símbolo ANS significa Acordo de Nível de Serviço, que será analisado a seguir.

\subsection{Acordo de Nível de Serviço - ANS}

Segundo Santos (2010), os Acordos de Nível de Serviços (ANS ou SLA do inglês Service Level Agreement), são utilizados como instrumentos de formalização do acordo entre cliente e provedor de serviço, com a função de definir o nível de qualidade do serviço a ser prestado pelo provedor.Para Lanze Lanz(2013), o ANS deve especificar os requisitos para o provedor planejar, estabelecer,implementar,operar, monitorar, analisar criticamente, manter e melhorar um Sistema de Gerenciamento de Serviços (SGS). Segundo esses autores, os acordos devem incluir "o desenho, a transição, entrega e melhoria dos 
serviços para cumprir os requisitos do serviço". (LANZ; LANZ, 2013).

Magalhães e Pinheiro (2007) afirmam que os princípios gerais para estabelecimento de ANS, independente do serviço oferecido, partem da aplicação da metodologia PDCA (Plan-DoCheck-Act), que inclusive consta da norma NBR ISO/IEC 20000-1:2011 da ABNT (2011), que trata de gestão de serviços e é mencionada como uma técnica de gerenciamento de qualidade para melhoria contínua no PMBOK do PMI (2013). A aplicação dos Acordos de Nível de Serviço iniciou no setor de Tecnologia da Informação (TI) que, com a rápida evolução tecnológica dos últimos quarenta anos, passou a ser fonte de inspiração da automação de vários serviços, com a contribuição da possibilidade de controles remotos de processos e comunicação, o que determinou sua inclinação para o setor de serviços. Essa característica da área de TI trouxe um nível de maturidade na gestão de serviços que foi imitado em outras áreas de conhecimento. (FERREIRA, 2011).

Segundo LaBounty (2008), os principais benefícios de um ANS, tanto para a corporação quanto para o cliente, são:

- estabelecer uma via de responsabilidade de mão dupla;

- criar níveis de serviço negociados e padronizados;

- documentar níveis de serviço;

- definir claramente critérios para a avaliação do serviço;

- fornecer uma base para melhoria de níveis de serviço;

- padronizar métodos para comunicar as expectativas de serviço.
Madalozzo (2012) orienta que para o Centro de Serviços Compartilhados (CSC), cuja atividade principal consiste em fornecer serviços com alto padrão de qualidade, ter indicadores sólidos de desempenho é essencial para o sucesso da organização de serviços. Esses indicadores devem compor a principal informação de comunicação com os clientes do CSC, contidos no ANS. A figura 2 representa esquematicamente o conteúdo do ANS.

Figura 2: Conteúdo do Acordo de Nível de Serviços (ou SLA do inglês Service Level Agreement)

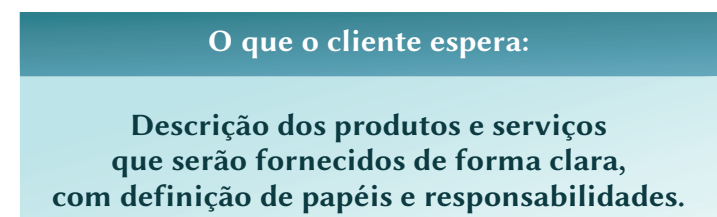

O que o CSC fornecerá:

Os requisitos dos serviços e as medidas de performance de acordo com o orçamento disponibilizado pela empresa.

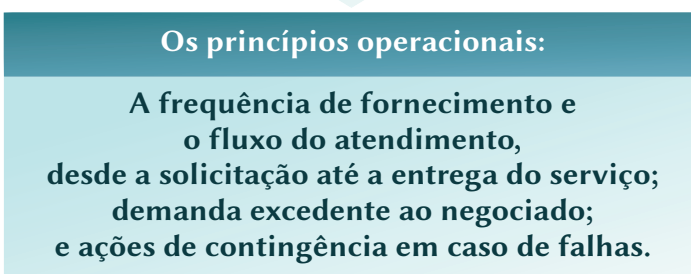

Metas e objetivos de melhorias:

Custo e requisitos de qualidade.

SLA reverso:

As atribuições do cliente.

Fonte: Do autor (2014) 
Para Lanz e Lanz (2013), o conteúdo básico de um ANS "é o mesmo de um contrato padrão de fornecimento de serviços" e deve conter os seguintes itens:

- definição e escopo detalhado do serviço/ produto (o que se inclui e o que se exclui);

- horário de atendimento e prestação de serviços;

- contatos e procedimentos para requisição de serviços;

- pré-requisitos do cliente;

- metas mensuráveis;

- disponibilidade;

- metas de desempenho/capacidade do serviço (tempo de resposta, volume), incluindo prazos limite para determinados dias;

- continuidade;

- segurança;

- padrões e procedimentos;

- definições e situações de emergência;

- reclamações e procedimentos de escalação;

- procedimentos de mudança;

- relatórios que devem ser produzidos;

- frequência das reuniões de revisão;

- contabilidade de custos e cobrança (se aplicável);

- regulamento de bônus/multas.

$\mathrm{Na}$ figura 3, estão representados os passos para elaboração do ANS propostos por Madalozzo (2012):
Figura 3: Processo de formalização do ANS

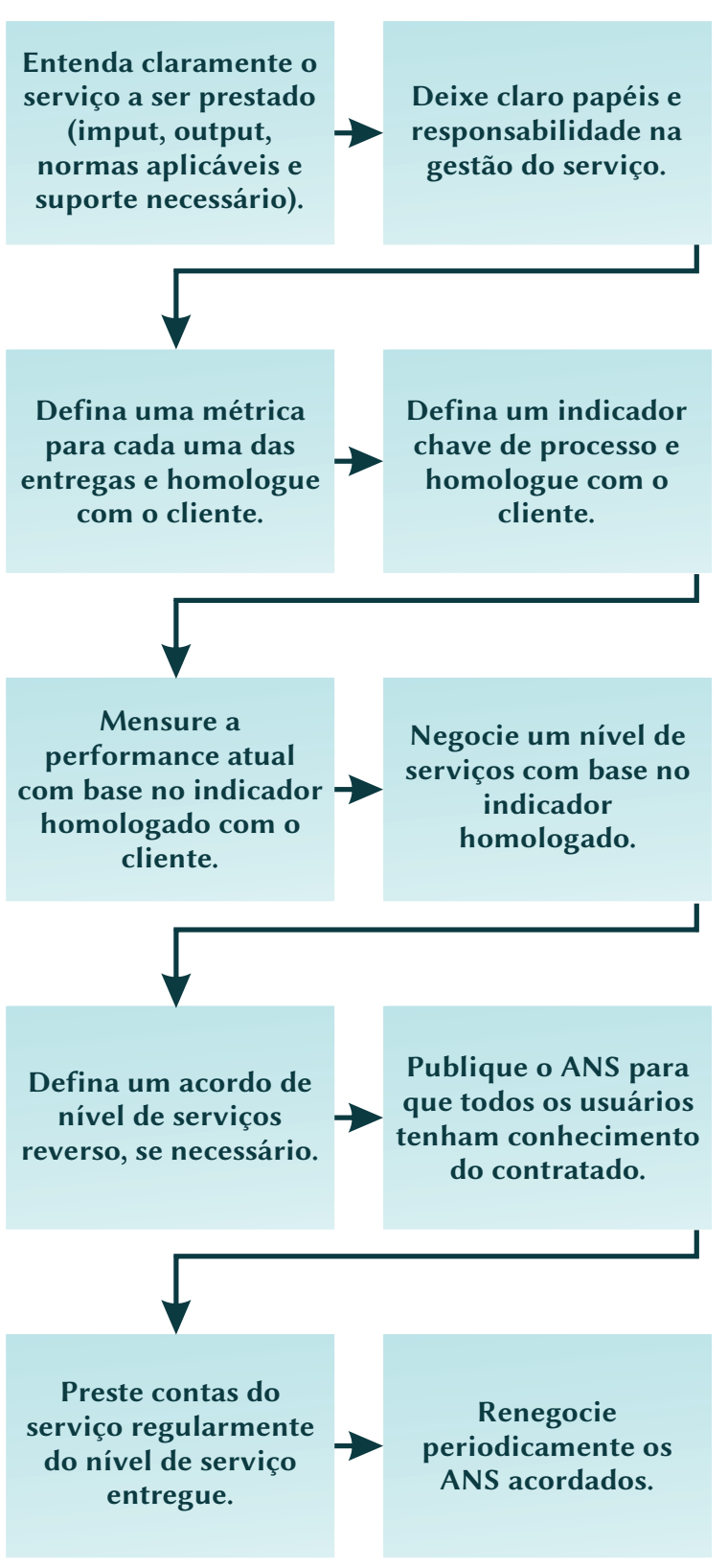

Fonte: Madalozzo (2012)

Segundo Grönroos (2009), os processos de serviço são coproduzidos com o cliente, havendo constantes interações intermediadas por ações de comunicação. A figura 4 representa esta interação, cuja gestão Grönroos (2009) chama de Marketing de Relacionamento. 


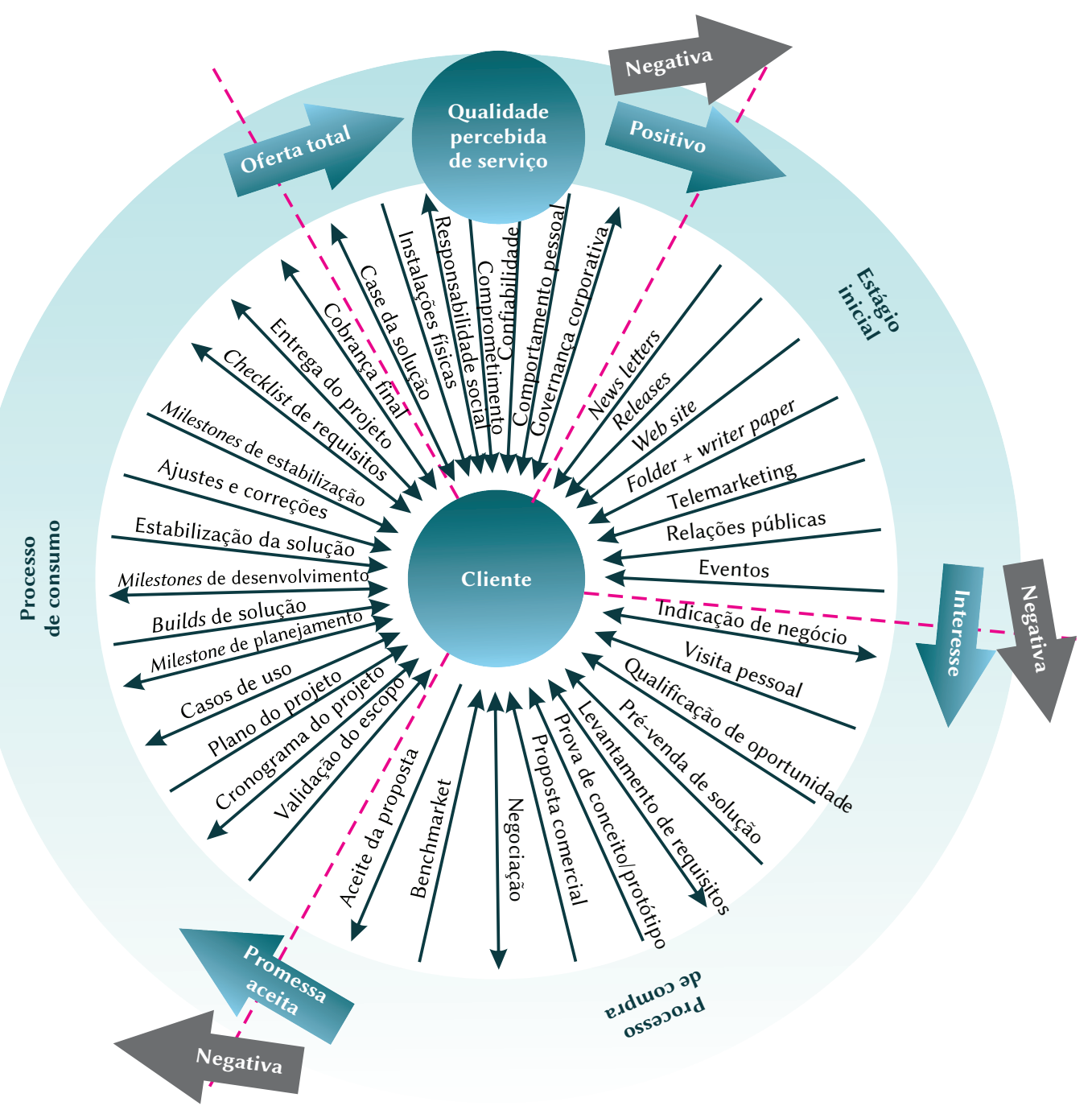

Fonte: Licks (2008)

Adotando a definição de Santos (2010) para o ANS de que este deve ser uma formalização do acordo entre cliente e provedor de serviço, para definir o nível de qualidade do serviço a ser prestado, é possível identificar neste mapa de relacionamento com o cliente apresentado em Grönroos (2009), na figura 4, que para a ANS deverão constar processos formalizados de compras, de consumo e da qualidade percebida pelo cliente.

A partir desses dois modelos de conteúdo de interação com o cliente, registros de sua satisfação e da qualidade percebida do serviço, serão propostos dois roteiros para prestação de serviço com a elaboração de um protótipo de Acordo de Nível de Serviço para a área de sustentabilidade de um Centro de Serviços Compartilhados (CSC).

\subsubsection{Serviços de Sustentabilidade}

Em 2012, os Estados Unidos movimentaram mais de 3 trilhões de dólares no mercado financeiro, nos chamados investimentos SRFs - do inglês Socially Responsible Funds, cuja traduçãolivre seria Fundos de Responsabilidade Social. A BM\&FBOVESPA utiliza o Índice de Sustentabilidade Empresarial (ISE) como 
benchmark na área de sustentabilidade empresarial para os investidores que negociam nesta bolsa e só permite a utilização deste índice para empresas de grande porte.(PEÇANHA,2012).

Essas são algumas demonstrações do impacto econômico que o tema sustentabilidade ou responsabilidade socioambiental está causando.

A vontade de tornar o entorno mais propício à sobrevivência é a motivação mais presente nos atos humanos. Essa vontade inspira esforços mais ou menos aprimorados e os resultados são medidos pela satisfação que retornam a seus agentes e àqueles que participam da ação, seja como coautores ou como espectadores.

O conceito de sustentabilidade é chamado de moderno porque até pouco tempo a guerra declarada pela humanidade aos reinos mineral, vegetal e animal demonstrava a "superioridade" da espécie humana. (MORIN, 1979).

Porém, a tentativa de subjugar o que deixou de existir está auxiliando a perceber a insanidade de alguns pressupostos que colocaram o ser humano contra o princípio primordial de sobrevivência.

Dos inúmeros exemplos, cita-se a dificuldade de obter água potável, energia, ar livre de agentes tóxicos, alimentos livres de contaminantes etc.

A evolução tecnológica e a disposição de informação têm colocado a humanidade em níveis de interação cada vez maiores, que tornam mais evidente a interdependência entre todos os elementos envolvidos no meio ambiente na determinação de como se dá o desenvolvimento desse meio, numa relação de causa e efeito cujo acompanhamento foi facilitado pela tecnologia.
Portanto, a sustentabilidade tornou-se a obviedade do uso de uma maior quantidade de informações para, dentro de uma relação de causa e efeito, determinar a longevidade de um empreendimento.

Dentro de uma relação sistêmica é possível alcançar entendimentos razoáveis sobre a sobrevivência, em que é necessária a manutenção de princípios colaborativos para manter presentes os elementos que contribuem para tal sobrevivência, ao invés da guerra contra todos os reinos proposta por Descartes. (MORIN, 1979).

A ANTIGA "NOVIDADE" DA SUS-

TENTABILIDADE ESTÁ MAIS E MAIS

PRESENTE EM SURPREENDENTES

EMPREENDIMENTOS HUMANOS

QUE DEMONSTRAM NÍVEIS DE

MANUTENIBILIDADE, RECONHECI-

DOS PELOS NÍVEIS DE SATISFAÇÃO

QUE TRAZEM A SEUS AUTORES,

COAUTORES E ESPECTADORES,

COM PERSPECTIVAS DE LONGA DURAÇÃO DE INTERAÇÕES.

São os empreendimentos sustentáveis, definidos por Teixeira e Boszczowski (2012), aqueles que envolvem "a identificação, criação e exploração de novos negócios que encontrem, no desenvolvimento econômico, a solução de um problema ambiental e social". (TEIXEIRA; BOSZCZOWSKI,2012,p.143).Essas autoras argumentam que "as falhas de mercado inerentes ao livre mercado, que promovem as externalidades e ineficiências que se refletem nos problemas ambientais e sociais do desenvolvimento de mercado" são vistas como oportunidades para o desenvolvimento de soluções economicamente 
viáveis pelos "empreendedores sustentáveis". (TEIXEIRA; BOSZCZOWSKI, 2012, p. 144).

A definição de sustentabilidade, que envolve os pilares economia, ambiente e sociedade, apresentando soluções para essas três esferas, é o viés largamente utilizado na literatura que trata sobre este conceito. (TEIXEIRA; BOSZCZOWSKI, 2012; ESTENDER; PITTA, 2008). Um panorama da linha do tempo da teoria sobre negócios sustentáveis é apresentado em Teixeira e Boszczowski (2012, p. 150), referenciado na figura 5.

Figura 5: Evolução e expansão do conceito de empreendedorismo sustentável

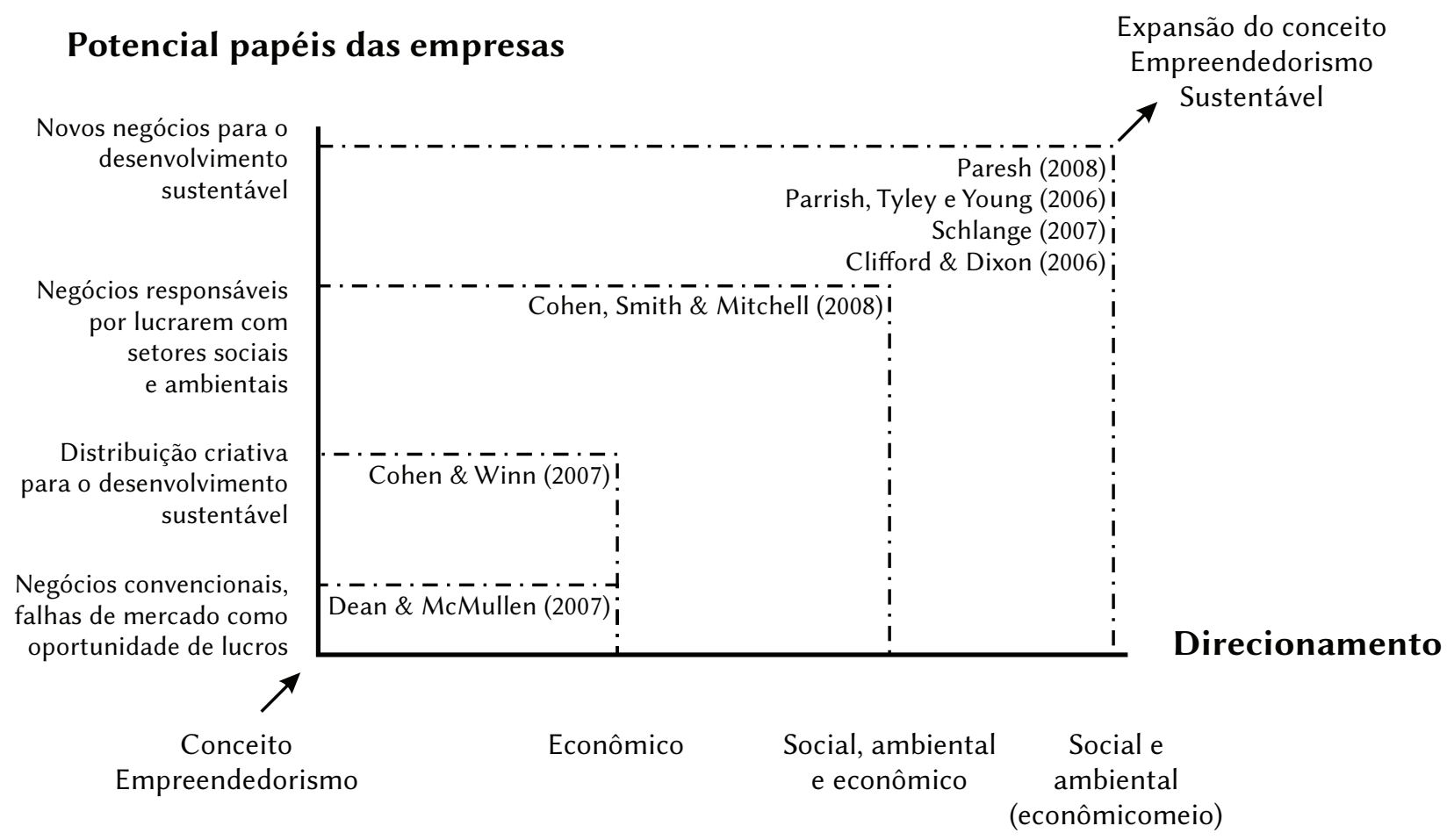

Fonte: Teixeira e Boszczowski (2012, p. 150) adaptado de Parrish (2008)

Como principais fontes de oportunidades, Teixeira e Boszczowski (2012, p. 150) mencionam: "mudanças na informação disponível para a sociedade sobre seus recursos materiais; mudanças nas interpretações ou preferências por meio de inovações culturais; mudanças no interpretador, no próprio ambiente em que ele está inserido", caracterizando tais oportunidades "como sendo aquelas que proporcionam aos empreendedores a possibilidade de solucionarem falhas de mercado ambientalmente relevantes de forma a aumentar o bem-estar social e promover o desenvolvimento sustentável da sociedade”.

E como oportunidades apontam-se as alternativas que possibilitam a um empreendimento tornar-se diferente de seus pares, dando-lhe possibilidade de melhores resultados relativamente a esses "concorrentes". Portanto, essas autoras mencionam a diferenciação competitiva que utiliza informações privilegiadas sobre oportunidades de oferta de soluções aos problemas sociais e ambientais que resultem em desenvolvimento econômico. 


\subsubsection{Sustentabilidade no CSC}

Neste contexto, um Centro de Serviços Compartilhados reúne a responsabilidade de ampliar o escopo de valores agregados aos produtos e serviços de seus clientes ao ofertar processos que thes permitam expandir suas fronteiras de produção ou, em outras palavras, que thes possibilite introduzir novos bens e serviços que maximizem, integradamente, a solução de problemas sociais, ambientais e econômicos da sociedade.

A seguir, serão listados alguns exemplos de Centros de Serviços Compartilhados que inseriram processos voltados para incrementar a sustentabilidade dos negócios de seus clientes.

A Petrobrás iniciou a implantação de seu CSC no ano 2000 e contou, desde então, com um processo chamado "Sistema de Gestão de Segurança, Meio Ambiente, Eficiência Energética e Saúde". (ENGEL, 2012). Dada a relevância socioambiental dos negócios praticados pela Petrobrás, é notório o nível de maturidade exigido de seu CSC neste quesito.

O CSC da Petrobrás, chamado de “Compartilhado"(ENGEL,2012) prevê,entre outros, alguns processos de apoio marcados por valores agregados pela gestão socioambiental, como:

- Gestão do conhecimento: sistematização da gestão do conhecimento, com a formalização e o registro dos conhecimentos essenciais para o funcionamento das unidades clientes.

- Precificação: ampliação da sistemática de repasse de custos aos clientes, definindo "pacotes de serviços"e sistemas de medição específicos para os pacotes. Como exemplo,
Engel (2012) cita o serviço "Gestão condominial”, em que são usados índices de desempenho que incluem itens de despesas referentes a aluguel - área (em metros quadrados), postos de segurança, energia, água, recepção, serviços de copa, estrutura para administrar etc.; a formalização dos custos poupados ou dispendidos evidencia a importância estratégica da gestão de recursos para as unidades e auxilia os clientes na construção dos preços de seus produtos.

- Segurança e saúde: aprimoramento da gestão de Segurança, Meio Ambiente e Saúde (SMS), nos processos de gestão de acidentes, de gestão do consumo de água e de energia (eficiência energética), nos projetos de construção e reforma (adotando requisitos de construção de edifícios verdes); aqui novamente há importante contribuição na precificação dos produtos e serviços dos clientes.

- Compras:incremento da gestão de compras verdes, em que as necessidades de compras das unidades clientes são avaliadas segundo critérios socioambientais, tais como eficiência energética, tempo de vida útil do bem, reciclagem, sistema de gerenciamento ambiental, embalagem, conteúdo do material, e design para reciclagem e separação. (JUNIOR; ANDRADE, 2009).

Monteiro et al. (2003) mencionam o caso da Shellquepossui,emseu CSC,umDepartamento de Gestão Ambiental e que coloca, a nível corporativo (unidades de negócio e CSC), o Desenvolvimento Sustentável como uma das perspectivas de seu Balanced Scorecard (BSC), ou seja, de sua própria estratégia, conforme demonstrado no Mapa Estratégico Hipotético de Marr et al. (2002), apresentado na figura 6. 
Figura 6: Mapa Estratégico Hipotético da Shell

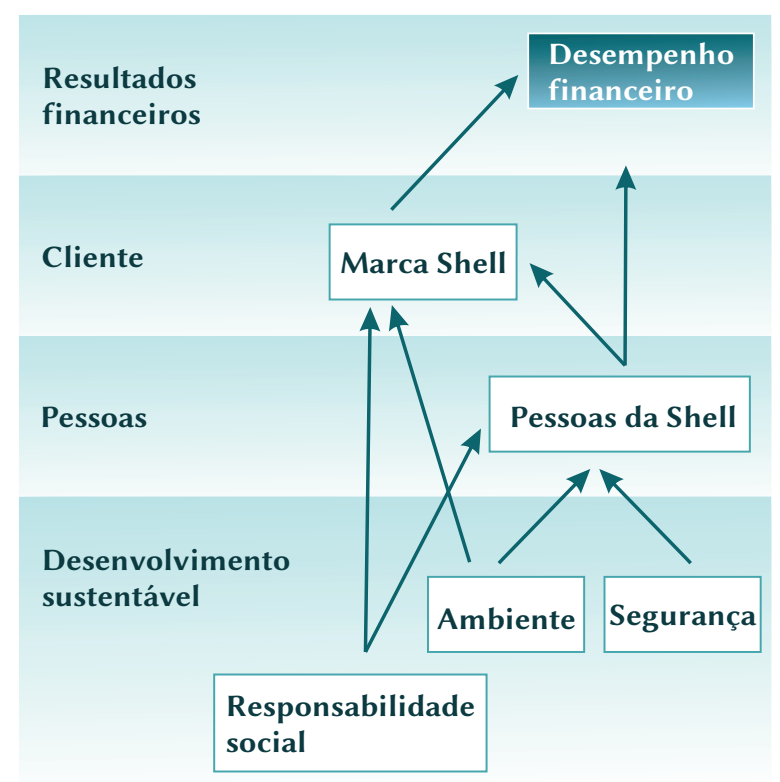

Zaine et al. (2011) apresentam uma lista de vantagens e desvantagens da inserção da dimensão sustentabilidade na estratégia empresarial, apresentada no quadro 4, que podem ser adotadas pelo CSC para analisar o cenário de aplicação de serviços de sustentabilidade.

Fonte: Adaptado de Marr et al. (2002)

Quadro 2: Vantagens e desvantagens da inserção da dimensão "sustentabilidade" na Estratégia Empresarial

\begin{tabular}{|c|c|}
\hline Vantagens & Desvantagens \\
\hline $\begin{array}{l}\text { - Redução do custo da produção e aumento da receita } \\
\text { tributária, com a venda dos subprodutos e a utilização } \\
\text { de serviços compartilhados. } \\
\text { - Diminuição do descarte de resíduos e melhoria da efici- } \\
\text { ência energética. } \\
\text { - Melhoria da imagem das empresas no mercado nacional e } \\
\text { internacional e da competitividade, com uso de tecnologias } \\
\text { sustentáveis e matéria-prima de baixo impacto ambiental. } \\
\text { - Fortalecimento da economia aliada a projetos sociais } \\
\text { (programas profissionalizantes e de treinamentos, edu- } \\
\text { cacionais e culturais, atividades comunitárias). } \\
\text { - Outras vantagens incluem as respostas das instituições } \\
\text { frente às pressões da sociedade, como, por exemplo, o } \\
\text { atendimento ao relatório socioambiental. }\end{array}$ & $\begin{array}{l}\text { - Despadronização quanto à classifica- } \\
\text { ção do subproduto. } \\
\text { - Desestímulo ao intercâmbio de subpro- } \\
\text { duto, devido à matéria-prima subsidia- } \\
\text { da pelo governo. } \\
\text { - Falta de ações do governo para incen- } \\
\text { tivar o intercâmbio do subproduto, em } \\
\text { vez de destiná-lo a aterros industriais. } \\
\text { - Distância entre os parceiros, que ten- } \\
\text { de a elevar o custo do transporte do } \\
\text { subproduto. } \\
\text { - Reaproveitamento, que pode pas- } \\
\text { sar a imagem de qualidade inferior. } \\
\text { (TANIMOTO, 2004). }\end{array}$ \\
\hline
\end{tabular}

Fonte: Zaine et al. (2011) 


\subsection{3 Îndices de Desempenho de Sustentabilidade}

Pires (2004) oferece uma definição de desempenho em que este é visto como "a informação quantificada do resultado obtido em processos, que pode ser comparada com metas, padrões, resultados passados e de outros processos". (PIRES, 2004 apud LUZ et al., 2006, p. 559).

Um dos principais motivos para adoção de Índices de Desempenho, além da questão de fornecer a informação mencionada por Pires (2004), necessária para decisões gerenciais, é o da comunicação institucional, objetivando contribuir de maneira decisiva para integrar a prática ao discurso da empresa.

Isso é válido também para a questão da sustentabilidade, em que os índices de desempenho, para incluir esta dimensão estratégica da empresa, deverão, segundo Smith et al. (2013), incluir os seguintes requisitos:

a) comunicação planejada como parte integrante da gestão sustentável;

b) respostas verdadeiras e positivas às ações ambientais da organização;

c) transformação de comportamentos em torno da visão de sustentabilidade empresarial;

d) integração de todos os processos por meio da comunicação,para que o modelo de negócio sustentável faça parte de todos os processos da empresa;

e) comunicação de forma ampla, ágil, inteligível, transparente e diferenciada, com múltiplos recursos de mídia adequados às partes interessadas (do inglês stakeholders), considerando as questões materiais e as necessidades de cada público de interesse.
Monteiro et al. (2003) destacam a adoção de novas ferramentas gerenciais ou adaptadas que pudessem dar uma abordagem mais efetiva à questão socioambiental. Como exemplos citaram a criação de Sistemas de Gestão Ambiental tais como Responsible Care Program, STEP, BS 7750, EMAS e ISO 14001, mencionando com destaque a utilização do Balanced Score Card (BSC), não como ferramenta, mas como um Sistema de Gestão Estratégica que pode, facilmente, incluir a dimensão da Gestão Socioambiental.

Para maior clareza sobre o BSC, toma-se a afirmação dos criadores deste sistema de gestão:

Os objetivos e as medidas utilizadas no Balanced Scorecard não se limitam a um conjunto aleatório de medidas de desempenho financeiro e não financeiro, pois derivam de um processo hierárquico (top-down) norteado pela missão e pela estratégia da unidade de negócios. (KAPLAN; NORTON, 1997: 09).

$\mathrm{Na}$ elaboração do BSC, os criadores do Scorecard, Kaplan e Norton recomendam: "começamos com a destinação. O que estamos tentando atingir? Se você observar a lógica do Scorecard, tudo apontará para as finanças". (KAPLAN; NORTON, 2001 apud NIVEN, 2005, p.144).

Nesta análise de Niven (2005), por definição, alguns índices financeiros deverão compor o grupo de resultado do BSC.

A discussão levantada por Monteiro et al.(2003) agregou, além da apresentação do BSC como Sistema de Gestão Estratégica que inclui a Gestão Ambiental, a análise da necessidade de criar uma dimensão específica de desenvolvimento sustentável ao invés de incluir essa dimensão nas quatro originais do modelo apresentado por Kaplan e Norton (1997). Essa questão é ilustrada na figura 7. 
Figura 7: Balanced Scored Card em cinco dimensões (acréscimo de Desenvolvimento Sustentável ao modelo original)

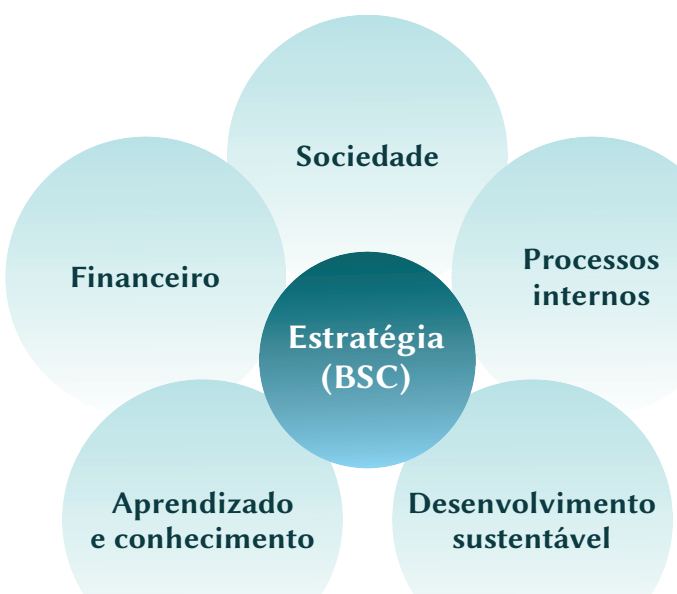

Fonte: Do autor (2014)
Monteiro et al. (2003) mencionam a existência de um Departamento de Gestão Ambiental no CSC e que o BSC pode ser utilizado como um meio de alinhar as metas do CSC às metas das áreas clientes, sob dois enfoques: o de parceria com as áreas clientes em que o BSC do cliente define os relacionamentos com o CSC e outro em que o Departamento de Gestão Ambiental é visto como um negócio independente e desenvolve seu próprio BSC, podendo contribuir com os clientes no alcance de suas metas.

Monteiro et al. (2003) analisam as diferentes formas de compor um BSC que incluam a dimensão de sustentabilidade e mencionam exemplos da utilização de índices por Centros de Serviços Compartilhados (CSCs), como os exemplos da Shell e da CETREL apresentados no quadro 3:

Quadro 3: Exemplos de Índices de Desempenho do BSC utilizados pela Shell e Cetrel

\begin{tabular}{|c|c|}
\hline Shell & Cetrel \\
\hline $\begin{array}{l}\text { Programa Minimum Health Management Standard (com- } \\
\text { posto por oito aspectos diferentes). } \\
\text { Incidentes fatais (meta =0). } \\
\text { Lost Time Injury Frequency (acidentes, termos de horas } \\
\text { paradas, por milhão de horas trabalhadas). } \\
\text { Auditoria ambiental; } \\
\text { Plano para melhoraro sistema de contabilidade ambiental. } \\
\text { Meio ambiente (derramamento). } \\
\text { Índice de consumo energético. } \\
\text { Implantação. }\end{array}$ & $\begin{array}{l}\text { №. de emergências ambientais. } \\
\text { Índice geral de conformidade ambiental. } \\
\text { \% de redução de impactos ambientais. } \\
\text { Redução da carga de poluentes } \\
\text { prioritários. } \\
\text { Índice de gestão ambiental (PNQ } \\
\text { ambiental). } \\
\text { Disponibilidade operacional global } \\
\text { (Estação de Tratamento de Efluentes). } \\
\text { Eficiência operacional global. } \\
\text { Índice de desempenho dosfornecedores. }\end{array}$ \\
\hline
\end{tabular}

Fonte: Monteiro et al. (2003) 
2.2 Proposta de Modelos de Acordos de Nível de Serviços para Serviços de Sustentabilidade

Para elaborar um modelo de Acordo de Nível de Serviços foi escolhido o serviço Gestão de Energia. Este serviço será descrito segundo exemplos de oferta de prática comum do mundo corporativo.

\subsubsection{Gestão de Energia}

O propósito da Gestão de Energia é tornar uma organização mais competitiva, inovadora, confiável, economicamente viável e contribuir para o desenvolvimento sustentável. Esta modalidade de gestão, no Brasil, contempla ações tais como optar pela melhor opção tarifária - devido ao considerável número de alternativas energéticas disponíveis-, a forma de contratação da energia, a adoção de medidas visando à eficiência energética, técnicas, ferramentas e equipamentos de medição e controle de energia eficazes, uso de índices de desempenho adequados aos processos da organização e apoio de sistema de gestão de informação sobre o uso dos recursos energéticos. (TONIM, 2009).

O modelo de gestão proposto pela ISO 50001 é aplicável a todos os tipos e tamanhos de organizações e baseia-se em elementos comuns às normas ISO de qualidade (ISO 9001) e meio ambiente (ISO 14001), possibilitando a integração a outros sistemas de gestão ou implementação separadamente.

A figura 8 apresenta alguns elementos comuns aos demais sistemas de gestão e outras peculiaridades originais.
Figura 8: Tópicos da ISO 50001

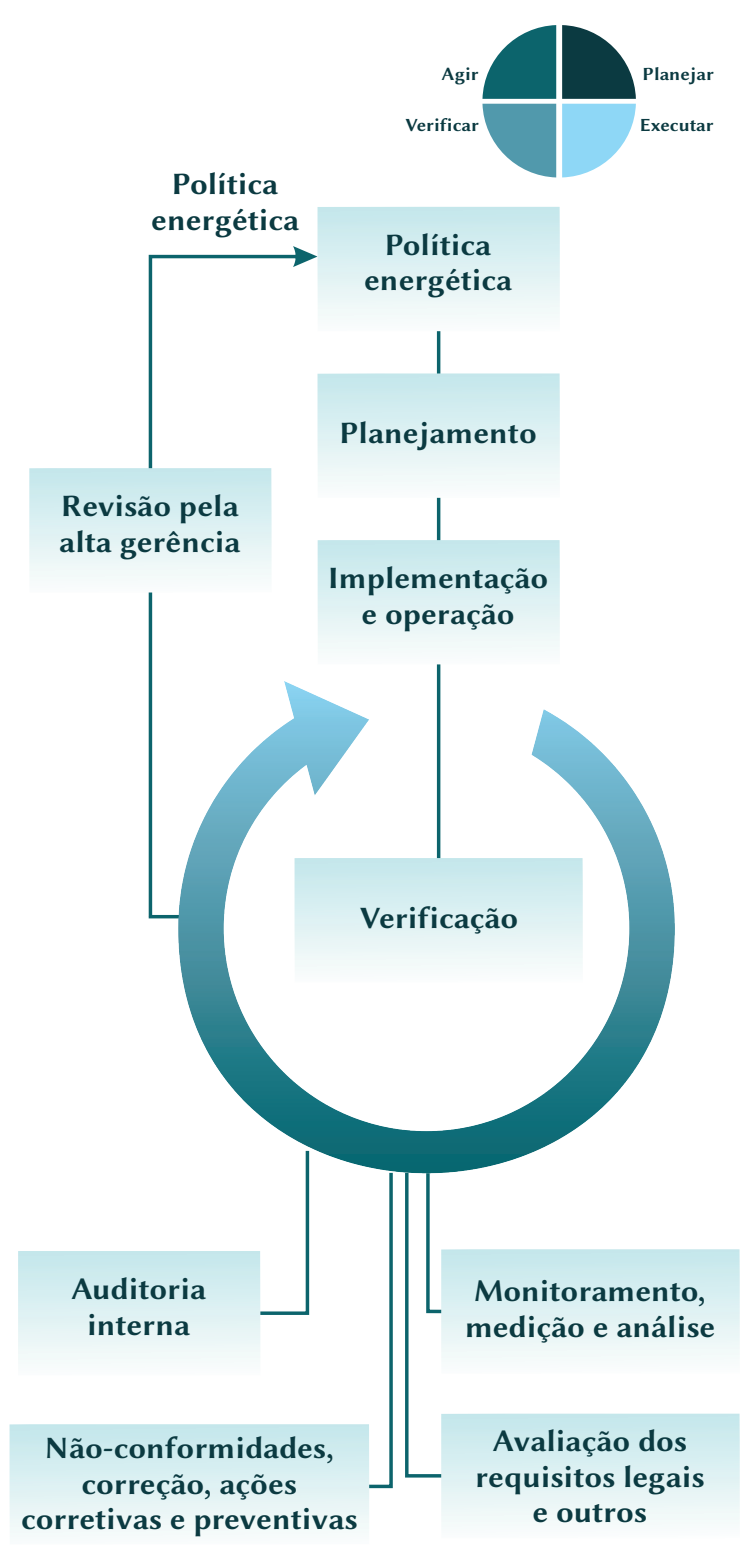

Fonte: ABNT NBR ISO 50001 (2011)

Baseado neste modelo, o Centro de Serviços Compartilhados pode oferecer apoio a seus clientes provendo uma política energética alinhada com a estratégia da corporação e realizar os demais passos de gestão:

- planejamento;

- implementação e operação; 
- verificação:

- monitoramento, medição e análise;

- avaliação de requisitos legais e outros;

- identificação de não conformidades, correção, ações corretivas e preventivas;

- auditoria interna;

- apresentar ações de melhoria contínua.

\subsubsection{Acordo de Nível de Serviço (ANS) para Gestão de Energia}

Conforme os requisitos para o ANS propostos por Grönroos (2009) e Lanz e Lanz (2013) e as orientações da ISO 50001, será apresentado um roteiro para elaboração deste tipo de contrato para o serviço de Gestão de Energia. A figura 9 apresenta esse roteiro.

Figura 9: Roteiro para prestação de serviço de Gestão de Energia

Escopo
- Primeiras visitas ao cliente para diagnóstico prévio
- Definição de abrangência e exclusividade do
serviço.
- Definição de fronteiras relevantes para
gestão (ABNT, 2011b): $1^{\mathrm{a}}$ entrega para o cliente.
Política energética
- Identificação da política energética a ser adotada
(metas, prazos, interações desejadas, representante
da alta direção do cliente).

Planejamento
- Detalhamento dos serviços a serem prestados, com
estimativa de carga horária e recursos a serem
disponibilizados tanto por parte do cliente quanto
do CSC.
- Detalhamento de entregas e prazos para estas
entregas.
- Alinhamento de disponibilidade de atendimento dc
CSC e do cliente, com definição de carga horária de
dedicação as etapas de prestação do serviço.

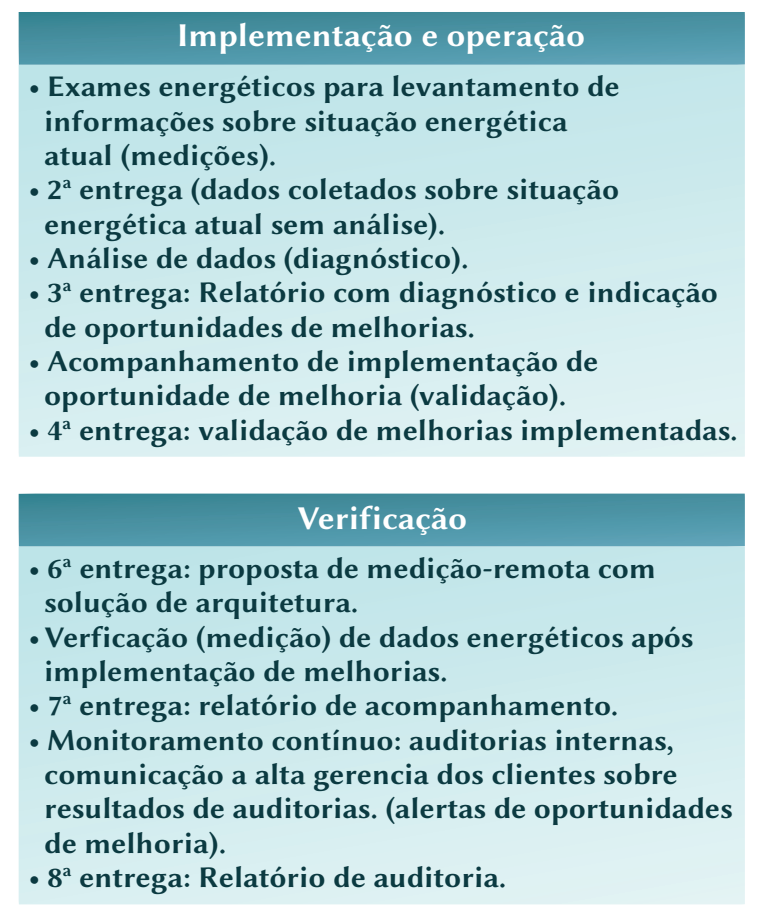

Fonte: Do autor (2014) 
A figura 10 apresenta as etapas do serviço de Gestão de Energia no ciclo PDCA:

Figura 10: PDCA e etapas da Gestão de Energia

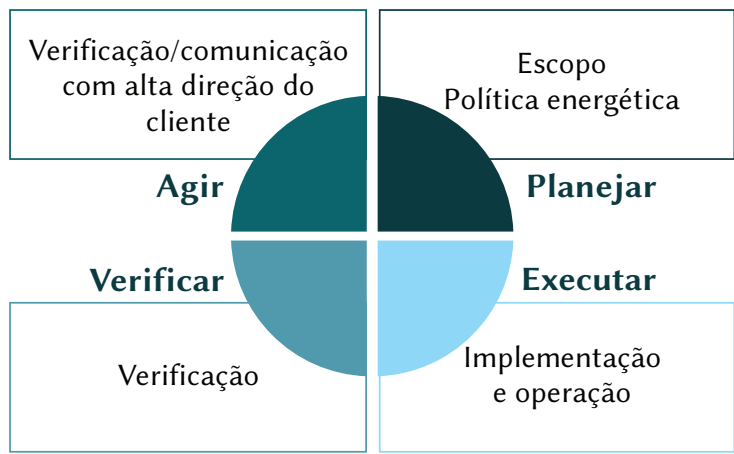

Fonte: Do autor (2014)
Em todas as etapas considera-se fundamental detalhar as atividades elencadas para sua execução,juntamente com a nomeação de pessoas responsáveis, estimativa de tempo, equipamentos envolvidos, custos, que deverão ser relacionados tanto ao CSC quanto ao cliente.

O modelo a seguir é um protótipo teórico recomendado como roteiro para a implementação do instrumento de gestão da satisfação do cliente. Devido à necessidade de consultá-lo constantemente e de que algumas das informações que constamnele serão inseridas aolongo da prestação do serviço, recomenda-se sua implementação em meio digital, com acesso das partes interessadas via rede (por exemplo internet), com controle de acesso de leitura e edição.

\section{Modelo de ANS}

A. Escopo do Serviço

\section{A.1 Público-alvo}

Descrição de empresas, grupos de pessoas, ou indivíduos isolados que serão usuários do serviço.

Discriminação de contatos (e-mail, telefone, Skype e outras possibilidades de comunicação como, por exemplo, nas redes sociais).

\section{A.2 Finalidade}

Definição do escopo do serviço, com esclarecimento de fronteiras de análise (ver conceito de fronteira na norma ABNT NBR 50001:2011).

Neste campo deve ser mencionada a política energética do cliente e representantes responsáveis do cliente (recomenda-se da alta gerência) e do fornecedor deverão confirmar este campo.

\section{A.3 Envolvidos}

Listagem de etapas previstas para prestação de serviços, relacionando os representantes do cliente para interação com o prestador de serviço para cada etapa, com confirmação por parte dos anotados da ciência de seu envolvimento. 


\section{B Planejamento}

\section{B.1 Descrição do serviço}

Detalhamento do serviço com descrição das etapas listadas no item 1.3.

\section{B.2 Cronograma de serviço}

Relação temporal das etapas. Sugere-se que a apresentação dessas relações seja feita com apoio de infográficos, linha de tempo, ou calendários como exemplos das figuras 11 e 12 .

Figura 11: Exemplo de calendário para descrever cronograma de execução de uma etapa do serviço

\begin{tabular}{|l|l|l|l|l|l|l|l|l|l|l|l|l|l|}
\hline & $00: 00$ & $01: 00$ & $03: 00$ & $05: 00$ & $07: 00$ & $09: 00$ & $11: 00$ & $13: 00$ & $15: 00$ & $17: 00$ & $19: 00$ & $21: 00$ & $23: 00$ \\
\hline DOM & & & & & & & & & & & & & \\
\hline SEG & & & & & & & & & & & & & \\
\hline TER & & & & & & & & & & & & & \\
\hline OUA & & & & & & & & & & & & & \\
\hline OUI & & & & & & & & & & & & & \\
\hline SEX & & & & & & & & & & & & & \\
\hline SÁB & & & & & & & & & & & & & \\
\hline
\end{tabular}

Figura 12: Exemplo de "Linha do Tempo" para descrever cronograma de execução de uma etapa do serviço

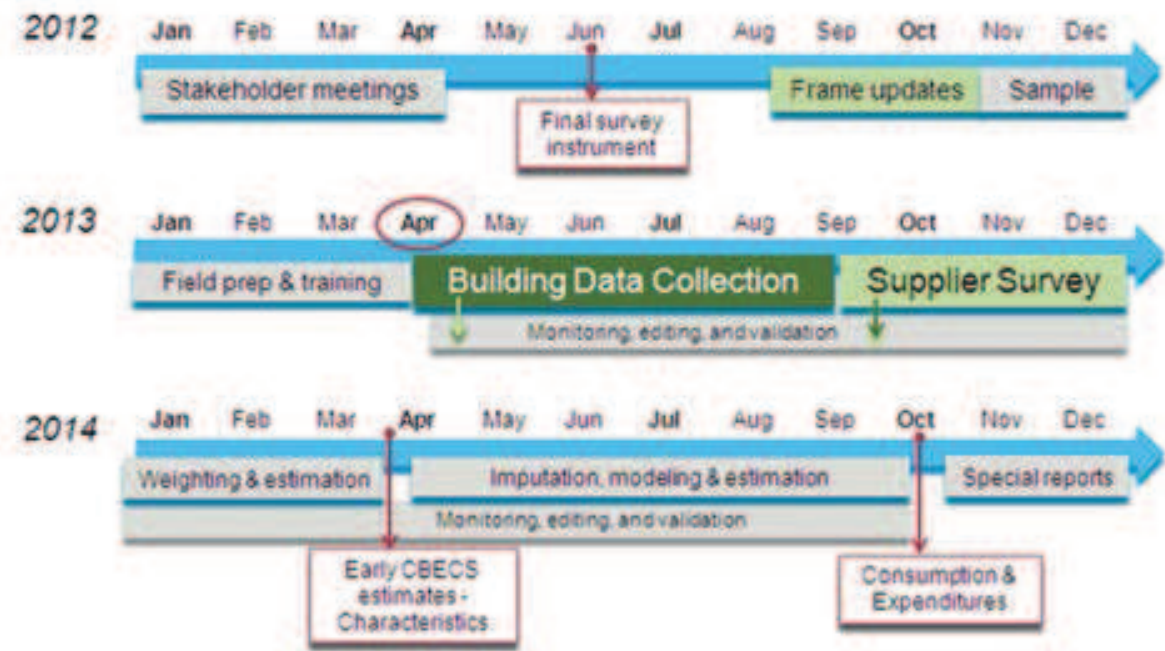

Fonte: U.S Energy Information Administration (2014) 


\section{B.3 Expectativas de entrega do serviço (disponibilidade)}

Acordo sobre tempo e, se possível, períodos de disponibilidade para atendimento por parte do fornecedor do serviço e também por parte do cliente em participar de atividades que demandem sua atenção.

Deve-se preparar campo para definição dos prazos e cargas horárias acordados com confirmação de responsáveis do cliente e do fornecedor do serviço.

Devem ser disponibilizados campos para anotação de entregas e respectivos prazos e cargas horárias utilizados com confirmação de responsáveis do cliente e do fornecedor do serviço. Essas marcações serão realizadas ao longo da execução do serviço.

\section{Implementação e operação}

As etapas constantes neste item são modulares, podendo o cliente contratá-las ou não.

\section{C.1 Medições}

Inspeções e medições para levantamento de informações sobre situação energética atual (ou de consumo e manejo de água).

Deverão ser listadas as seguintes informações:

- descrição da atividade;

- descrição das variáveis medidas ou observadas segundo Sistema Internacional de Medidas;

- equipamentos utilizados para medição, com descrição de fabricante e modelo e número de série (para rastreamento);

- períodos de medição - em meses, semanas, dias, horas ou segundos, conforme necessidade de clareza;

- responsável pela medição (fornecedor);

- responsável pelo acompanhamento (cliente).

Esta etapa de medição gera relatórios que devem ser encaminhados ao cliente conforme cronograma estabelecido no item B.3. 


\section{C.2 Análise e diagnóstico}

Nesta etapa são realizados análises e diagnósticos com descrição de oportunidades de melhoria alinhadas com a política energética/gestão de água.

Esta etapa deve fornecer as seguintes informações:

- relatório com diagnóstico e indicação de oportunidades de melhorias;

- nome do(s) responsável(is) pela análise;

- nome do(s) responsável(is) pelo acompanhamento e recebimento do relatório de diagnósticos;

- período e carga horária utilizados para análise (a ser anotado no item B.3).

\section{C.3 Acompanhamento de implementação}

OCentro de Serviços Compartilhados pode disponibilizar equipe para implementação das oportunidades de melhoria ou não. Em caso positivo, deve ser acrescentado ao ANS o subitem "Implementação de Melhorias”. Esta fase de execução do serviço de Gestão de Energia/Água deve ser acordada previamente, na etapa de escopo e planejamento.

O acompanhamento é a garantia de que a execução das implementações seguirá as recomendações do CSC.

Informações necessárias para esta etapa:

- nome do responsável do fornecedor do serviço para acompanhamento de melhorias;

- nome do responsável do cliente para acompanhamento de melhorias;

- datas de visitas e cargas horárias ocupadas;

- relatório com validação de melhorias implementadas com marcação de entregas no item B.3. 


\section{Verificação}

\section{D.1 Verificação de resultados de melhorias}

Inspeções e medições para levantamento de informações sobre situação energética (ou de consumo e manejo de água) após implementação de melhorias.

Deverão ser listadas as seguintes informações:

- descrição da atividade;

- descrição das variáveis medidas ou observadas segundo Sistema Internacional de Medidas;

- equipamentos utilizados para medição, com descrição de fabricante e modelo e número de série (para rastreamento);

- períodos de medição - em meses, semanas, dias, horas ou segundos, conforme necessidade de clareza;

- responsável pela medição (fornecedor);

- responsável pelo acompanhamento (cliente).

Esta etapa de verificação gera relatórios que devem ser encaminhados ao cliente conforme cronograma estabelecido no item B.3.

\section{D.2 Medição remota}

Apresentação de proposta de fornecimento de serviço de medição remota do manejo de energia/água do cliente. As seguintes informações são relevantes para este processo:

- arquitetura de rede, hardware (medidores) e softwares para acompanhamento remoto de variáveis relevantes para os índices de desempenho da política de energia/água do cliente;

- entrega de especificações da arquitetura do sistema de monitoração remota ao cliente, com marcação no item B.3;

- prazos para validação de proposta (responsável: cliente), implementação de sistema de monitoramento remoto (responsável: fornecedor), início da operação da medição (responsável: fornecedor), frequência de relatórios, referenciados ao item B.3;

- acordo de setpoints (referências) para alertas sobre manejo de energia/água no cliente;

- acordo sobre níveis de controle remoto sobre consumo de energia/água do cliente por parte do fornecedor do serviço;

- validação do cliente de modelo de relatório de acompanhamento;

- nome de responsável do cliente para validação deste processo;

- nome do responsável do fornecedor por gerir este processo;

- relatórios de acompanhamento (com modelo previamente validado pelo cliente), com marcação de datas de entregas no item B.3. 


\section{D.3 Auditoria interna}

A auditoria é uma etapa semelhante àquela de medição e diagnóstico (subitens C.1 e C.2) que pretende estabelecer pontos de contato entre normas (por exemplo, a ISO 50001 para Gestão de Energia) e as disposições legais vigentes e as políticas de gestão do cliente, enfatizando aqueles pontos que estão em conformidade e outros não conformes.

A auditoria interna gera o relatório que deve ser encaminhado à alta direção do cliente para que este possa acionar o movimento de melhoria contínua.

Esta etapa deve fornecer as seguintes informações:

- escopo do trabalho (requisitos legais analisados e de referência, fronteiras analisadas, restrições);

- descrição das atividades de medição e situações avaliadas;

- descrição das variáveis medidas ou observadas segundo Sistema Internacional de Medidas;

- descrição de equipamentos utilizados para medição, com informação sobre fabricante e modelo e número de série (para rastreamento);

- períodos de medição - em meses, semanas, dias, horas ou segundos, conforme necessidade de clareza;

- nome do(s) responsável(is) pela auditoria (fornecedor);

- nome do(s) responsável(is) pelo acompanhamento e recebimento do relatório de diagnósticos;

- relatório de auditoria com diagnóstico e indicação de oportunidades de melhorias e situações de conformidade e não conformidade segundo os critérios utilizados (normas, políticas de gestão e outros requisitos legais).

- período e carga horária utilizados para auditoria (a ser anotado no item B.3).

\section{Conclusão}

A facilidade de acesso a informações e a conectividade alcançada pelo atual estado tecnológico levaram à completa reformulação dos paradigmas de negócios. De todas as perspectivas apresentadas por Grönroos (2009), percebe-se que a de Serviços é onipresente. O Centro de Serviços Compartilhados representa a potencialização desta perspectiva em que a gestão dos relacionamentos entre unidades de uma organização foca nessa dimensão do serviço.
Dentre os serviços de apoio que o CSC pode prover, o universo da sustentabilidade aumenta o horizonte de soluções, já que sua abrangência abriga interesses econômicos, ambientais e sociais.

O exemplo de serviço abordado neste trabalho representa claramente os benefícios alcançados pelos clientes de um CSC em atender seus próprios interesses baseados na análise proposta pela sustentabilidade. 
O Acordo de Nível de Serviço (ANS) representa a gestão da satisfação do cliente e, para o CSC, é a ferramenta que condensa formalmente a interação entre fornecedor (CSC) e clientes, o que pode ser um norteador inclusive de como o serviço deverá acontecer. É vital que o ANS não represente a rigidez da relação, mas sim expresse o interesse e a satisfação do cliente, bem como as capacidades e ações do fornecedor.

O roteiro para oferta dos serviços de Gestão de Energia é genérico e pode ser utilizado para o acompanhamento de outros serviços tais como gestão de águas, manutenção e setor de obras.

O Brasil passa por momento relevante para a Gestão de Energia, já que órgãos tais como a AgênciaNacionaldeEnergiaElétrica(ANEEL), concessionárias de energia, Operador Nacional do Sistema Elétrico (ONS), Banco Nacional do Desenvolvimento (BNDES) e outras instituições nacionais e internacionais estão incentivando programas de eficiência energética e de gestão de energia. Os incentivos variam desde redução em taxas de juros para financiamentos de projetos de eficiência energética até fundos perdidos, o que torna urgente a formação de massa crítica, especialmente nos CSCs que possibilitem aplicar esses recursos na melhoria do desempenho de seus clientes. O ganho estimado para o CSC é duplo, pois o investimento para suas ações na área de Gestão de Energia pode ser financiado por uma fonte de apoio e o serviço pode ser custeado por seus clientes. 


\section{SUSTAINABILITY AS A Business Opportunity For Shared SERVICES CEnTRES}

\begin{abstract}
Sustainability is a source of innovative initiatives to makeproducts andservices moreattractive. The Shared Services Centre (CSC) seen as a driver of business areas is the natural repository of sustainability-related services to its customers. This paper intends to propose a roadmap for service that increases the sustainability of the CSC users. Systematic research was performed on the topic of Sustainability Shared Services Centre to provide a sense of how this issue is being described in the literature. Therefore, a literature research of service issue was carried on, then on the Shared Services Centre, addressing the issue of quality of service, to then get to the Service Level Agreement as an instrument of management of customersatisfaction and registration of the various interactions needed between CSC (supplier) and your client. To offer an example of supportingsustainability of a CSC Customer service was described a management system that is inserted into the environmental dimension: Energy Management.
\end{abstract}

\section{REFERÊNCIAS}

ABNT, Associação Brasileira de Normas Técnicas. NBR ISO/IEC 20000-1: 2011 - Tecnologia da informação - Gestão de serviços - Parte 1: Requisitos do sistema de gestão de serviços. 2011.

\section{. Catálogo. ABNT NBR ISO}

50001:2011b. Sistemas de gestão da energia - Requisitos com orientações para uso. Disponível em: <http://www.abntcatalogo. com.br/norma.aspx?ID=087286 $>$. Acesso em: 28 maio 2013.

AFFONSO, Henrique José. Centro De Serviços Compartilhados (Csc): Impactos da Implementação do Modelo na Estratégia, na Estrutura e na Gestão de Empresas do Setor Privado. Tese de Doutorado em Administração. Universidade FUMEC Faculdade de Ciências Empresariais, 2010, Belo Horizonte-MG. Disponível em: <http://www.fumec.br/anexos/cursos/ mestrado/dissertacoes/completa/henrique jose_affonso.pdf >. Acesso em: 10 abr. $201 \overline{4}$.

ALCOA S. A. Sobre a Alcoa. 2010. Disponível em: <http://www.alcoa.com/brasil/pt/info_page/ sobre_a_alcoa.asp $>$. Acesso em: 12 abr. 2014.

BAYARDINO, Renata Argenta. A Petrobras e o desafio da sustentabilidade ambiental. Monografia de Bacharelado, Universidade Federal do Rio de Janeiro, Instituto de Economia, 2004.

CORRENTE, Claudia. Smartwater network. Apresentação Prezi, postada em 24/02/2014. Disponível em: <http://prezi. com/uyy006xriqz_/smart-water-networkpor/>. Acesso em: 29 maio 2014.

ENGEL, Maurílio H. Corrêa. Centro de Serviços Compartilhados na Petrobras “Compartilhado". 2012.

ESTENDER, Antonio Carlos; PITTA, Tercia de Tasso Moreira. O conceito do desenvolvimento sustentável. Revista Terceiro Setor, v. 2, n. 1, 2008.

FERREIRA, Glauce Regina Cardoso. A Atuação Da Divisão De Serviços Gerais: Diseg Como Prestadora De Serviços Do Instituto De Tecnologia Em Imunobiológicos/Fiocruz. 2011, XX f. Tese De Doutorado. Universidade Federal do Rio De Janeiro, 2011. 
FUNDAÇÃO VANZOLINI. Referencial técnico de certificação: Edifícios

habitacionais - Processo AQUA. Disponível em: <http://www.vanzolini.org.br/>. Acesso em: 29 maio 2014.

\section{GRÖNROOS, C. Marketing -}

Gerenciamento e Serviços. 2. ed. Rio de Janeiro: Campus, 2009.

ISO. Disponível em: <http://www.iso.org/ iso/home/news_index/news_archive/news. htm? refid=Ref1618 >. Acesso em: 30 maio 2014.

JÚNIOR, Antônio Costa Silva; ANDRADE, José Celio. Oportunidades para Compras Verdes no Setor de Suprimentos de Petróleo Brasileiro S.A. Contextus - Revista Contemporânea de Economia e Gestão. v. 7, n. 1, p. 69-80, jan./ jun. 2009. (69-80)

KAPLAN, Robert S.; NORTON, David P. A Estratégia em Ação: balanced scorecard. Tradução de Luiz Euclides Frazão Filho. 15. ed. Rio de Janeiro: Campus, 1997.

\section{Organização Orientada para a}

Estratégia: como empresas que adotam o Balanced scorecard prosperam no novo ambiente de negócios. Tradução de Afonso Celso da Cunha Serra. 4. ed. Rio de Janeiro: Campus, 2001.

\section{"On Balance" (No Equilíbrio).}

CFO, fevereiro de 2001, pp. 73-77.

KIM, W. Chan; MAUBORGNE, Renée. A estratégia do oceano azul: coma criar novos mercados e tornar a concorrência irrelevante. Rio de Janeiro: Campus, 2005.

KOHL, Cláudia Adriana; SELLITTO, Miguel Afonso. Avaliação do desempenho ambiental de um operador de serviços logísticos por indicadores categóricos. Estudos Tecnológicos em Engenharia, v. 5, n. 3, p. 284-301, 2009.

\section{LABOUNTY, Char. "How to To}

Establish and Maintain Service Level

Agreements", 2008.HDI Focus. Disponível em: <http://www.hdibrasil.com.br/ index2.php?option $=$ com_content $\&$ do pdf=18id=379>. Acesso em: 26 nov. 2008.

LANZ, Luciano Quinto; LANZ, Renata. Acordos e Gerenciamento de Níveis de Serviço. Artigo postado em 24/10/2013 by Midias Sociais em <http://pmkb.com. br/acordos-e-gerenciamento-de-niveis-deservico/>. Acesso em: 13 abr. 2014.
LICKS, Manoel. Marketing de relacionamento. 2008. Disponível em: <http://licksrs.blogspot. com.br/2008/06/marketing-de-relacionamento. html? showComment=1398695034424>. Acesso em: 20 abr. 2014.

LUZ, Sheila O. C.; SELLITTO, M.; GOMES, Luciana P. Medição de desempenho ambiental baseada em método multicriterial de apoio à decisão: estudo de caso na indústria automotiva. Gestão \& Produção, v. 13, n. 3, p. 557-570, 2006.

MADALOZZO, Renato Murilo. Serviços Compartilhados. Apostila utilizada como livro de apoio didático ao Curso MBA Gestão de Serviços Compartilhados do SENAI/SC. Florianópolis, 2012.

MAGALHÃES, Ivan Luizio; PINHEIRO, Walfrido Brito. Gerenciamento de Serviços de TI na Prática. São Paulo: Novatec, 2007.

MAKOWER, J. A economia verde: descubra as oportunidades e os desafios de uma nova era dos negócios. Tradução: Célio Knipel Moreira. São Paulo: Gente, 2009.

MARR, Bernard; NEELY, Andy; THOMAS, Geoff; CLARK, Bruce. Intangible Drivers of Corporate Performance at Shell International, Centre for Business Performance, Cranfield School of Management, 2002. Encontrado em: $<$ http://www.cranfield.ac.uk>. Acesso em: 10 jul. 2003.

MEISTER, Denise Inês Tonello. Avaliação de programa de conservação de água para um clube de eventos. Monografia apresentada para obtenção do título de Especialista no Curso de Pós Graduação em Construções Sustentáveis, Departamento Acadêmico de Construção Civil, Universidade Tecnológica Federal do Paraná, UTFPR. Curitiba, 2012.

MONTEIRO, Paulo Roberto Anderson; CASTRO, Alexandre Ramos; PROCHNIK, Victor. A mensuração do desempenho ambiental no Balanced scorecard e o caso da Shell Brasil. VII Encontro Nacional sobre Gestão Empresarial e Meio Ambiente, FGV/USP, Outubro de 2003.

MORIN, Edgar. O paradigma perdido: a natureza humana. Europa América, Portugal 1979.

NIDUMOLI, Ram; PRAHALAD, C. K.; RANGASWAMI, M. R. Why Sustainability is Now the Key Driver of Innovation. Harvard Business Review. Canada, September, p. 3-4, 2009. 
PARRISH, B. D. Sustainability-Driven Entrepreneurship: A Literature Review. Leeds, UK: University of Leeds, 2008.

PEÇANHA, Reynaldo Schirmer. ISE Índice de Sustentabilidade Empresarial. Certificação e sustentabilidade ambiental: uma análise crítica, p. 88. Certificação e sustentabilidade ambiental: uma análise crítica / organização de Jacques Marcovitch. - São Paulo, 2012. 148 p. Trabalhos de conclusão da disciplina EAD-5953 Estratégias Empresariais e Mudanças Climáticas, oferecida pelo Departamento de Administração da FEA-USP, primeiro semestre de 2012.

\section{PIRES, S. Gestão da cadeia de}

suprimentos (supply-chain management): conceitos, estratégias, práticas e casos. $\mathrm{S}$. Paulo: Atlas, 2004.

\section{PMI - PROJECT MANAGEMENT}

INSTITUTE. Um Guia do Conhecimento em

Gerenciamento de Projetos - Guia PMBOK. 4. ed. Newtown Square, Pennsylvania, USA: Project Management Institute, 2013.

QUINN, B., COOKE, R., KRIS, A. Shared Services: Mining for Corporate Gold. Financial Times Prentice Hall, 2000.

SANTOS, Moreno Becker. Gestão da mudança: a unificação da área de serviços a pessoas da Braskem no Rio Grande do Sul. 2010.

\section{SCHARF, Regina. Manual de Negócios}

Sustentáveis. São Paulo: Amigos da Terra, 2004.

SMITH, Vivian Paes Barretto; DE MACEDO, Luiz Carlos; MENDES, Flávia Cristina Martins. Estratégia socioambiental $\mathrm{O}$ papel estratégico da Comunicação Organizacional na economia verde e de baixo carbono. XV ENGEMA - Ética e sustentabilidade socioambiental na empresa inovadora. Pontifícia Universidade Católica de São Paulo - PUC/SP. São Paulo, 2013.

SOARES, Caroline C. B., RUNTE Gabriel F. C. Aplicação Da Metodologia Do Balanced Scorecard Numa Estrutura De Centro De Serviços Compartilhados. 2012, XX f. Tese (Doutorado em Engenharia de Produção) Universidade Federal do Rio de Janeiro, 2012.
TANIMOTO, A.H. Proposta de Simbiose Industrial para minimizar os resíduos sólidos no Polo Petroquímico de Camaçari. 2004, XX f. Dissertação (Mestrado Profissional em Gerenciamento e Tecnologias Ambientais no Processo Produtivo) Universidade Federal da Bahia, Salvador, 2004

TEIXEIRA, Rivanda Meira; BOSZCZOWSKI, Anna Karina. O empreendedorismo sustentável e o processo empreendedor: em busca de oportunidades de novos negócios como solução para problemas sociais e ambientais. Revista Economia \& Gestão, Pontifícia Universidade Católica de Minas Gerais, v. 12, n. 29, maio./ago. 2012.

TONIM, Gilberto. A gestão de energia elétrica na indústria - seu suprimento e uso eficiente. 2009. Tese de Doutorado. Universidade de São Paulo.

ZAINE, Mariselma Ferreira; FROTA, Mauro de Moraes. Parques Eco-Industriais como Instrumento de Sustentabilidade. 9o Simpósio de Ensino de Graduação da UNIMEP - Universidade Metodista de Piracicaba. Piracicaba, 2011.

U.S Energy Information Administration. Commercial buildings energy consumption survey. 2014.

Disponível em: <http://www.eia.gov/consumption/ commercial/>. Acesso em: 30 maio 2014.

Data de recebimento: 29/07/14

Data de aprovação: 29/10/14 


\section{SOBRE O AUTOR}

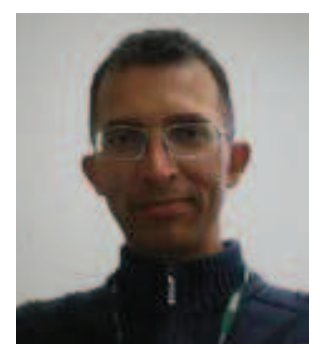

\section{Luís Fabiano Celestrino}

É especialista em Gestão de Serviços Compartilhados (MBA pelo SENAI/SC) e em Engenharia Elétrica pela UniversidadeFederaldeSanta

Catarina(UFSC).Égraduado em engenharia elétrica pela UFSC (1996) e possui experiência em gestão de projetos (PMBOK e Gestão Ágil SCRUM). Tem experiência na área de Engenharia Elétrica, com ênfase em Eletrônica Industrial,Sistemas e Controles Eletrônicos, Instalações Elétricas Industriais, Acionamentos Eletrônicos de Motores e Gestão de Energia. Participou de consultoria em projetos de inovação a empresas do setor sucroalcooleiro do Noroeste do Paraná. Está envolvido com gestão de equipes em projetos de educação profissionalizante e de pesquisa e desenvolvimento em automação industrial, além de coordenar a equipe da Olimpíada do Conhecimento do SENAI Florianópolis.

\section{***}

